\title{
Influence of deep magma-induced thermal effects on the regional gas outburst risk of coal seams
}

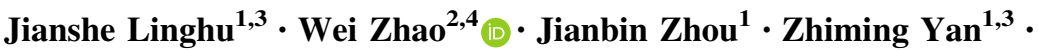 \\ Kai Wang ${ }^{2,4} \cdot$ Chao $\mathrm{Xu}^{1,2,4} \cdot$ Chuanwen $\mathrm{Sun}^{2,4}$
}

Received: 22 November 2020/Revised: 17 January 2021/ Accepted: 24 June 2021 / Published online: 19 July 2021

(C) The Author(s) 2021

\begin{abstract}
The thermal effect caused by deep magma intrusion can not only accelerate the metamorphism of coal body, but also bring additional thermal field that changes the mechanical environment of coal seams, thereby affecting the permeability of coal seams. Different from shallow coal resources, deep coal resources are in a mechanical environment characterized by limited stress and strain. Thus, the thermal effect has a more significant influence on the distribution and permeability characteristics of deep coal seams. In this study, the evolution history of highly metamorphic coal seams in Yangquan mining area was analyzed, and the main effect of magmatic activity on coal seams was obtained. Based on the determined vitrinite reflectance data of typical mines in Yangquan mining area, the maximum paleotemperature was calculated by adopting the Barker's method. Furthermore, the paleotemperature distribution in Yangquan mining area was summarized, and its relationship with the metamorphic degree was acquired. Then, a new permeability model considering the thermal strain was proposed to analyze the permeability evolution in deep coal seams at different ground temperatures. Finally, through a combination of the results of gas pressure and outburst number in Sijiazhuang Mine, Yangquan No. 5 Mine and Xinjing Mine, the influence of ground temperature on the gas outburst risk in Yangquan mining area was explored. The following conclusions were drawn: The maximum paleotemperature in Yangquan area can be $303{ }^{\circ} \mathrm{C}$. In addition, the paleotemperature in the south is higher than that in the north of Yangquan mining area. The various temperatures at different depths bring about different degrees of thermal stress to different coal seams, leading to different strains. Under the fixed displacement boundary conditions in the deep, the coal seam folds and bends to varying degrees. Moreover, the difference in the ground temperature raises the $a$ value of coal seams and lowers the permeability, which promotes the formation of gas-rich zones and increases the risk of coal seam outburst. The research results can help mines to make proper gas disaster prevention plan for different zones.
\end{abstract}

Keywords Gas outburst - Metamorphic degree - Geological structure - Thermal evolution · Yangquan mining area

Wei Zhao

381zhao@cumtb.edu.cn

1 Huayang New Material Technology Group Co., LTD., Yangquan Shanxi 045000, China

2 Beijing Key Laboratory for Precise Mining of Intergrown Energy and Resources, China University of Mining and Technology (Beijing), Beijing 100083, China

3 State Key Laboratory of Coal and Coalbed Methane CoMining, Jincheng Shanxi 048012, China

4 Risk Management and Safety Engineering School, China University of Mining and Technology (Beijing), Beijing 100083, China

\section{Introduction}

The regional magmatic thermal process in a mining area not only affects the metamorphic degree of the coal seam, but also determines the development of coal pores and the occurrence of coal seam gas (Jiang et al. 2011; Zhao et al. 2020a; Zhao et al. 2020b; Wang et al. 2011; Wang et al. 2013; Fu et al. 2020; Xin et al. 2020). At the same time, the non-uniform thermal stress produced by magma intrusion into the coal seam will change the stress distribution in the region, forming local structures such as faults and folds (Jiang et al. 2011; Cao et al. 2018; Jiang et al. 2015). As the 
mining ranges of coal mines in Yangquan mining area expand to the surrounding and extend to the deep, the folds and gas outburst hazards in coal seams increase gradually. Compared with shallow coal seams, the permeability boundary of deep coal seams changes from the uniaxial strain condition to the isovolumetric condition, and the coal seam is more sensitive to strain than to stress (Liu et al. 2016). Therefore, the thermal strain variation caused by a slight change in the deep thermal temperature field significantly alters coal seam permeability. Grasping the distribution of magmatic rock, exploring the evolution and distribution characteristics of ground temperature, and analyzing its influence on the gas occurrence and outburst risk in a coal seam in Yangquan mining area play a vital role in coal mining and gas control. In this paper, the regional thermal evolution history of Yangquan mining area was analyzed, and the distribution of regional paleotemperature difference was obtained based on the Barker's method. After that, the microscopic influence of thermal evolution on the mechanical strength, stress state and gas incubation conditions of coal seams in the mining area was investigated by means of direct measurement or indirect inference of relevant parameters, and the influence of the additional thermal temperature field on regional outburst risk distribution was explored. Finally, the classification of outburst risk difference was verified through the macroscopic characteristics of outburst accident distribution and gas pressure distribution. The framework of research idea is shown in Fig. 1.

\section{General situation of regional geology in Yangquan mining area}

Yangquan mining area, a typical NNE synclinal structure located in the mid-east region of Shanxi Province, the northeast of Qinshui Basin and the west wing of Taihang Mountain anticline (Fig. 2), is an important base to produce anthracite in China. Affected by the multi-stage activities of Indosinian, Yanshanian and Himalayan periods in history, its structural morphology and combination form have altered to different degrees. At present, the main coal-bearing strata in the mining area are the Carboniferous Taiyuan Formation and the Permian Shanxi Formation, and the main mining coal seams are the No. 3 , No. 8 and No. 15 coal seams whose average buried depths are 383, 416, $522 \mathrm{~m}$, respectively (Guo et al. 2016). Although all the mineable coal seams in the mining area belong to high-rank anthracite, their volatile contents vary. Horizontally, the volatile content is higher in the western and northern coal seams. Vertically, the lower coal seams possess a higher volatile content than the upper ones. For example, the average volatile contents of the No. 3, No. 12 and No. 15 coal seams are $9.55 \%, 9.49 \%$ and $8.40 \%$, respectively. Since the volatile content is inversely proportional to the metamorphic degree, the western and northern coal seams and the deep coal seams are of higher metamorphic degrees.

The metamorphic degree of coal body is closely related to ground temperature, and the high-temperature magmatic activity often accelerates the coal metamorphism process. As far as Yangquan mining area is concerned, the main magmatic activity periods are Hercynian, Yanshanian and Himalayan. Magmatic metamorphism includes two types, namely the regional magmatic thermal metamorphism (RMTM) without direct contact with magma and the contact metamorphism (CM) with direct contact with magma (Wang et al. 2014, 2017; Cheng et al. 2009; Zhao et al. 2015, 2019; Tang et al. 2018). According to the geological data, magma intrusion mainly occurs in three regions in the mining area, namely the Yinying and Suohuang regions in the north (Hercynian period), the Yuxian region in the north (Yanshanian period), and the Xiyang-Pingding region and the east of Zuoquan region in the south (Himalayan period) (Wang et al. 2013; Tang et al. 2018; Feng et al. 2014). It can be concluded that the magmatic rocks in Yangquan mining area are basically distributed in the north and south ends of the mining area, but no large area of magma intrusion into coal seams has been found in the current mining range. The study (Pu et al. 2012) shows that the high metamorphic degree of coal in the north of Qinshui Basin results from the regional magmatic thermal process. Specifically, magmatic heat brought by deep magma intrusion leads to the regional paleotemperature anomaly and significantly raises the metamorphic degree of coal. Therefore, the magmatic activities in this area primarily induce RMTM rather than CM. In addition, magmatic rocks can push and lift coal seams by applying tectonic stress, which will change the local stress environment and form local dynamic metamorphism (Fig. 3). For example, magma overflow occurred in Fushan mountain and Fenghuangshan mountain in Xiyang in the east of Yangquan No. 2 Mine, forming pillars in the basement of coal seam; furthermore, these pillars develop into small faults.

\section{Back-calculation of regional paleotemperature distribution in Yangquan mining area}

The regional paleotemperature can be retrospectively analyzed through vitrinite reflectance measurement. Based on the reaction kinetics equation, Sweeney et al. (1990) gave a formula for vitrinite reflectance measurement with ground temperature as an independent variable. This formula is suitable for deriving the vitrinite reflectance variation with time when the ground temperature is known. 


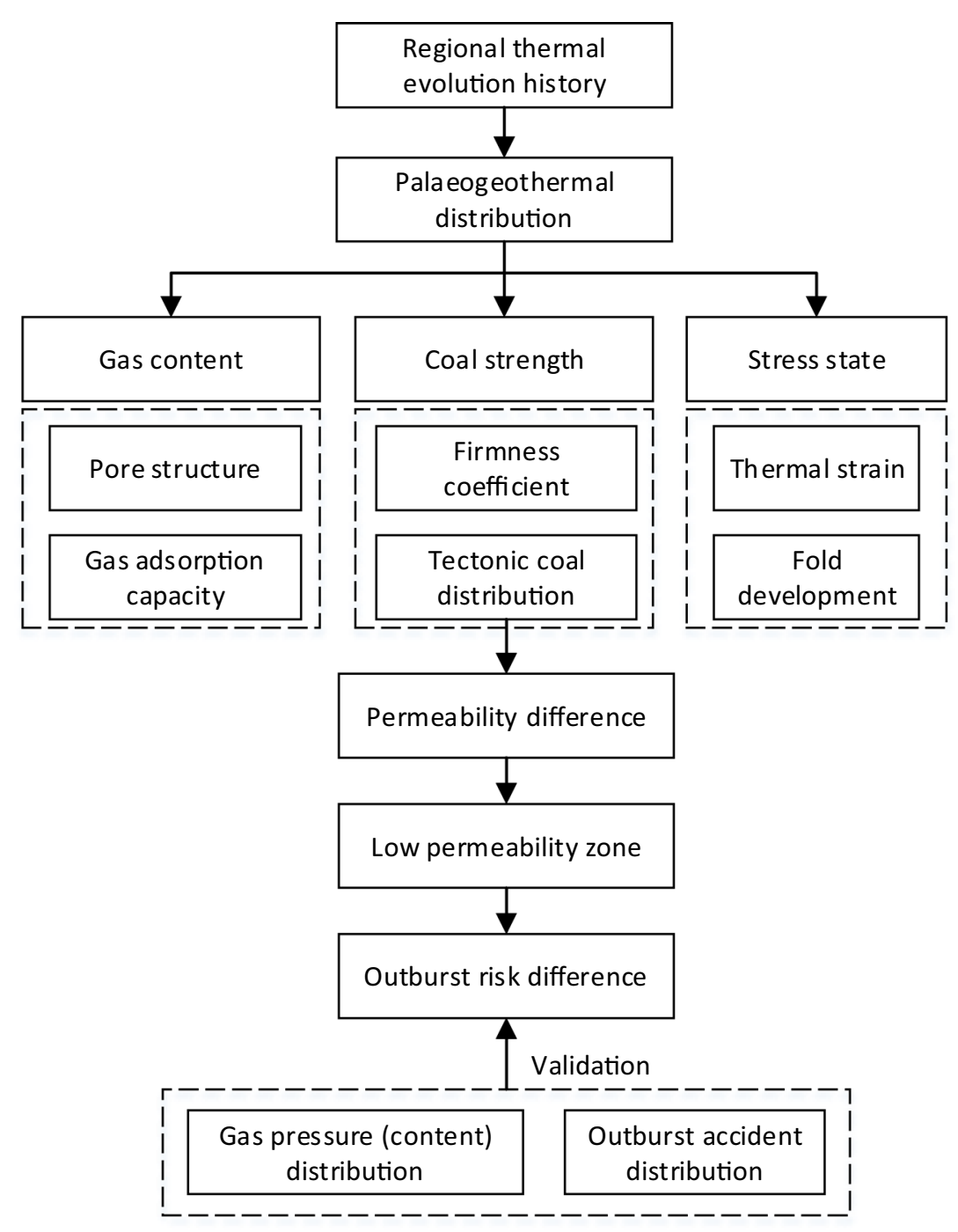

Fig. 1 Framework of research idea

Jiang et al. (2011) gave an empirical relationship between the vitrinite reflectance of coal and the maximum thermal evolution temperature during the contact of magmatic rocks with coal. The maximum paleotemperature can be directly derived in accordance with this empirical relationship:

$T_{\text {peak }}=\left[\operatorname{In}\left(\bar{R}_{\mathrm{o}, \max }\right)+1.19\right] / 0.0078$

where, $T_{\text {peak }}$ is the maximum temperature of magma thermal evolution, ${ }^{\circ} \mathrm{C}$.

As Eq. (1) is an empirical formula, its validity needs to be verified. Cheng et al. (2009) once calculated the maximum paleotemperature in Qinshui Basin by adopting the method of apatite fission track and vitrinite reflection modelling. Their calculation reveals that when the vitrinite reflectance is 2.39 , the maximum paleotemperature is 266 ${ }^{\circ} \mathrm{C}$, while the maximum paleotemperature calculated by Eq. (1) under the same vitrinite reflectance is $264^{\circ} \mathrm{C}$. The difference is only $2{ }^{\circ} \mathrm{C}$, which verifies the validity of Eq. (1).

To investigate the variation of coal seam ground temperature in Yangqu mining area, the vitrinite reflectance data from Xinyuan Mine, Xinjing Mine, Yangquan No. 1 Mine, Yangquan No. 5 Mine and Sijiazhuang Mine from north to south were collected in sequence (Table 1). In addition, to enhance the integrity of the data and avoid the influence of the large change in the buried depth on the research results, the vitrinite reflectance measurement data of some mines in Yangquan mining area in the literature $\mathrm{Li}$ et al. (2015) were also included in Table 1, and all of them are the test data of the same coal seam (the No. 15 coal seam). It can be found that the vitrinite reflectance of Xinyuan Mine is 2.3\%; that of Xinjing Mine is $2.29 \%-$ $2.65 \%$, with an average of $2.47 \%$; that of Yangquan No. 1 Mine is $2.59 \%$; that of Yangquan No. 5 Mine is $2.90 \%-$ 


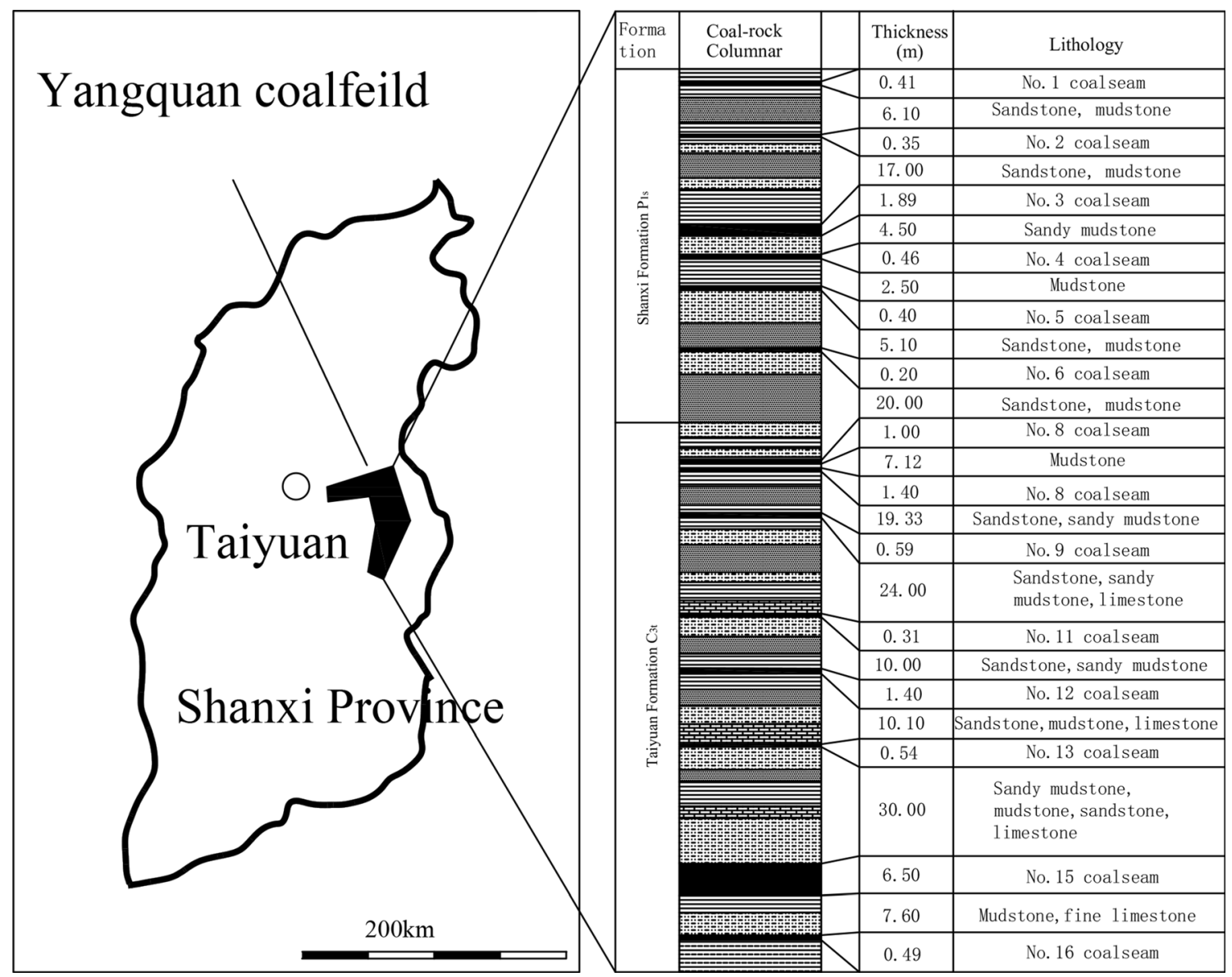

Fig. 2 Basic geological characteristics of Yangquan mining area

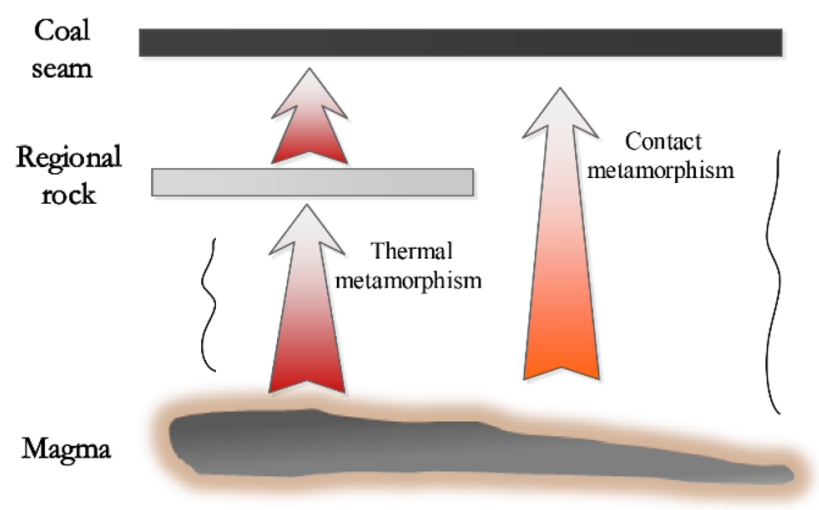

Fig. 3 Schematic diagram of the influence of magma on the occurrence of coal seam in Yangquan mining area

$2.98 \%$, with an average of $2.94 \%$; and that of Sijiazhuang Mine is $2.35 \%-3.25 \%$, with an average of $2.88 \%$.

The calculated results of paleotemperature according to Eq. (1) are illustrated in Fig. 4. It can be found that the maximum thermal evolution temperatures of the No. 15 coal seam in the five mines are 259, 277, 274, 292 and 303
${ }^{\circ} \mathrm{C}$, respectively, and the paleotemperature in Yangquan mining area tends to be higher in the south and lower in the north. Therefore, the magmatic activity in the south of the mining area has a relatively far-reaching influence on the metamorphic degree of the coal seam. This is inconsistent with the fact that magmatic rocks are distributed in both the north and the south of the mining area during the evolution of the geological structure. The main reason is that the magmatic activity occurred in the south of the mining area during the Himalayan period, which means that this region experienced RMTM for three stages. Therefore, the thermal metamorphism was more intense during the Himalayan period. That is, the warming events in the XiyangPingding region and the east of Zuoquan region exert a greater impact on the metamorphic degree of coal.

After the coal seam is subjected to high temperature, the cooling process will last for a long time due to the small thermal conductivity. It is assumed that the cooling process of a coal seam is a semi-infinite medium thermal diffusion similar to plate cooling (Zhang et al. 2008). Then, the cooling process can be expressed by Eq. (2): 
Table 1 Maximum vitrinite reflectance in Yangquan mining area

\begin{tabular}{llll}
\hline $\begin{array}{l}\text { Sample } \\
\text { No. }\end{array}$ & Sampling site & $\begin{array}{l}\text { Coal } \\
\text { seam }\end{array}$ & $\begin{array}{l}\text { Average maximum } \\
\text { vitrinite reflectance (\%) }\end{array}$ \\
\hline 1 & Xinyuan Mine & 15 & 2.3 \\
2 & Xinjing Mine & 15 & 2.29 \\
3 & Xinjing Mine & 15 & 2.65 \\
4 & Yangquan No. 1 Mine & 15 & 2.59 \\
5 & Yangquan No. 5 Mine & 15 & 2.96 \\
6 & Yangquan No. 5 Mine & 15 & 2.9 \\
7 & Yangquan No. 5 Mine & 15 & 2.92 \\
8 & Yangquan No. 5 Mine & 15 & 2.92 \\
9 & Yangquan No. 5 Mine & 15 & 2.98 \\
10 & Yangquan No. 5 Mine & 15 & 2.98 \\
11 & Yangquan No. 5 Mine & 15 & 2.94 \\
12 & Sijiazhuang Mine & 15 & 2.88 \\
13 & Sijiazhuang Mine & 15 & 2.35 \\
14 & Sijiazhuang Mine & 15 & 3.03 \\
15 & Sijiazhuang Mine & 15 & 3.25 \\
\hline
\end{tabular}

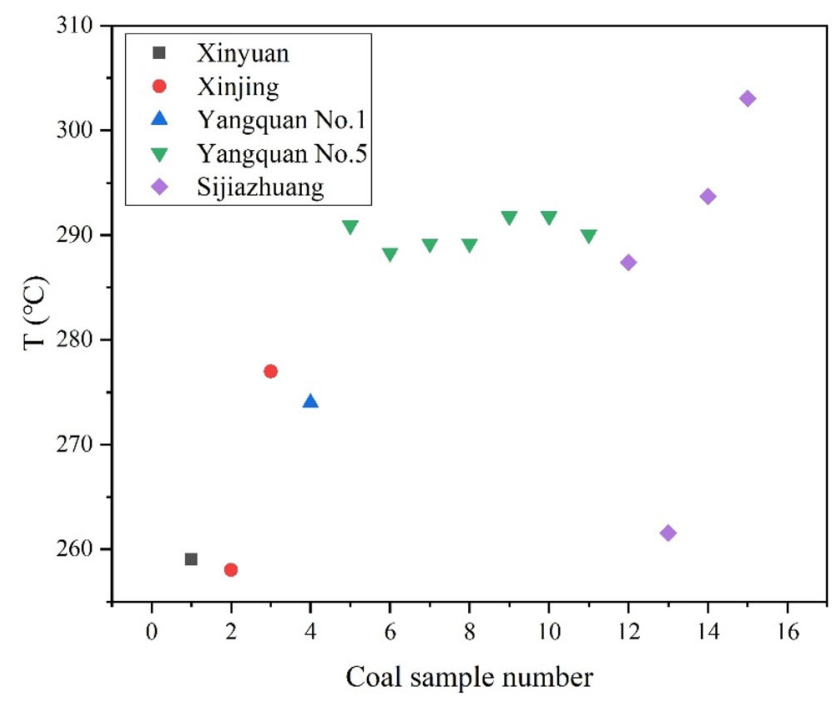

Fig. 4 Comparison of paleotemperatures in typical mines of Yangquan mining area

$T_{t}-T_{\infty}=\left(T_{\text {peak }}-T_{\infty}\right) \operatorname{erfc} \frac{x}{2 \sqrt{D_{\mathrm{T}} t}}$

where, $T_{t}$ is the temperature at time $t ; T_{\infty}$ is the termination temperature which is assumed to be $30{ }^{\circ} \mathrm{C} ; T_{\text {peak }}$ is the peak temperature, taking the maximum paleotemperature of Sijiazhuang Mine as the input value, $303{ }^{\circ} \mathrm{C} ; D_{\mathrm{T}}$ is the thermal diffusivity; $x$ is the length from the contact surface.

Generally speaking, the thermal diffusivity of rock is on the order of $10^{-6}-10^{-7} \mathrm{~m}^{2} / \mathrm{s}$ (Zhang et al.2008). Assuming that the thermal diffusivity of coal is $1 \times 10^{-7} \mathrm{~m}^{2} / \mathrm{s}$, Eq. (2) can be solved by MATLAB software, and the

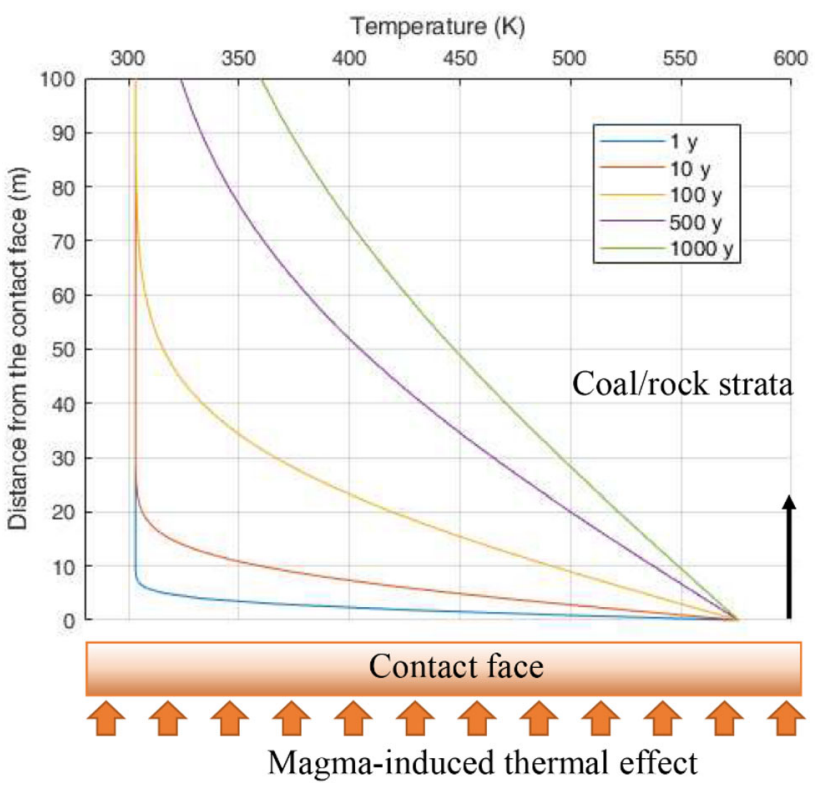

Fig. 5 Evolution of temperature in coal and rock strata

diagram of temperature distribution at different cooling times can be obtained (Fig. 5). It can be found that as time passes by, the coal seam and the lower strata gradually cool at a decelerating rate.

\section{Influence of ground temperature distribution on coal seam gas outburst risk in Yangquan mining area}

\subsection{Effect of deep additional thermal temperature field on the microscopic pore structure of coal seam}

According to the pore classification method proposed by Hodot, the pores in coal can be divided into four types: macropores $(1000 \mathrm{~nm}<$ pore size $\leq 100,000 \mathrm{~nm})$, mesopores $(100 \mathrm{~nm}<$ pore size $\leq 1000 \mathrm{~nm})$, small pores $(10 \mathrm{~nm}<$ pore size $\leq 100 \mathrm{~nm}$ ) and micropores (pore size $\leq 10 \mathrm{~nm}$ ) (Zhao et al. 2008). Among them, the volume of micropores determines the adsorption capacity of coal. RMTM will increase the volume and specific surface area of micropores in the coal seam, thereby increasing its gas adsorption capacity (Jiang et al. 2011). Figure 6 exhibits the pore volumes of Xinjing Mine, Yangquan No. 5 Mine and Sijiazhuang Mine determined by the mercury intrusion experiment in the literature $\mathrm{Wu}$ et al. (2005); Yangquan Coal Industry (Group) Co., Ltd., (2018a, b). Overall, Sijiazhuang Mine corresponds to the largest pore volume (up to $0.10 \mathrm{~mL} / \mathrm{g}$ ), followed by Yangquan No. 5 Mine $(0.0534 \mathrm{~mL} / \mathrm{g})$, and Xinjing Mine corresponds to the smallest pore volume $(0.0286 \mathrm{~mL} / \mathrm{g})$. A combination 
between the pore volume results in Fig. 6 and the paleotemperature results in Fig. 4 discloses that the pore volume increases with the rise of paleotemperature. Sijiazhuang has the highest paleotemperature and the greatest pore volume.

The change in the adsorption capacity ( $a$ value) can directly reflect the influence of thermal metamorphism on gas adsorption characteristics. Researches show that thermal metamorphism can increase the volume of micropores and thereby promoting the adsorption capacity (Jiang et al. 2011; Wang et al. 2014). During the investigation on the influence of magmatic thermal action on coal seam occurrence, adopting the $a$ value method can effectively reduce the errors caused by geological caprock and other gas escape conditions. The measured $a$ values of main coal seams in different mines of Yangquan mining area are compared in Fig. 7. Vertically, the $a$ value is larger at a greater buried depth. Horizontally, the $a$ values of the four mines follow the order: Sijiazhuang $>$ No. $5>$ Xinjing $>$ Xinyuan, that is, the adsorption capacity of the southern coal seam is greater than that of the northern one, which is consistent with the paleotemperature distribution in Yangquan mining area.

\subsection{Effect of deep additional thermal temperature field on the mechanical strength of coal seam}

The firmness coefficient reflects the strength of coal structure and indirectly reflects the in-situ stress in the area where the coal structure is located. Figure 8 presents the firmness coefficients of the No. 15 coal seam in three mines determined according to the national standard (Part 12: Methods for Determining Coal Firmness Coefficient in Methods for Determining the Physical and Mechanical Properties of Coal and Rock, GB/T 23,561.12-2010). As

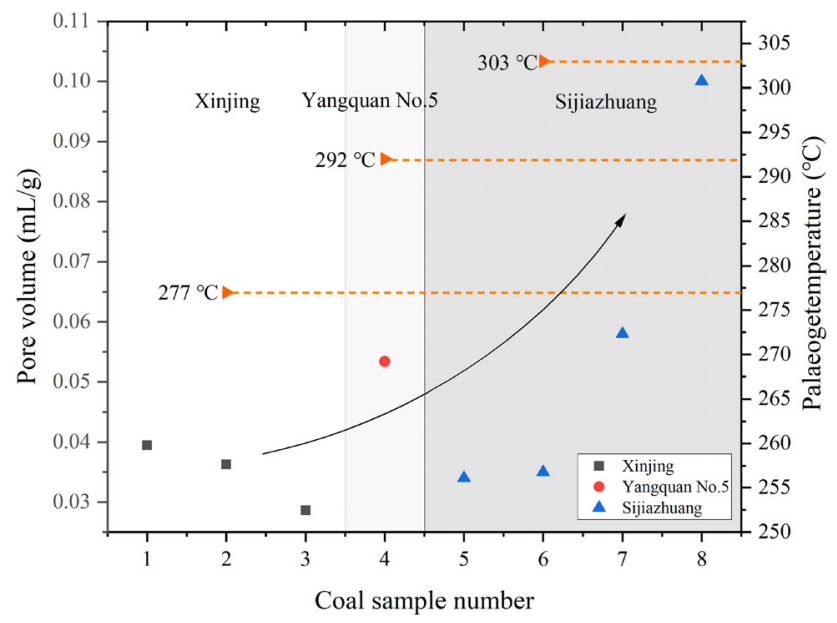

Fig. 6 Results of pore volumes in typical mines of Yangquan mining area obtained by the mercury intrusion experiment illustrated in Fig. 8, the average firmness coefficient of the No. 15 coal seam in Sijiazhuang Mine (0.37) is much smaller than those of Yangquan No. 5 Mine and Xinjing Mine ( 0.85 and 0.87 , respectively), which indicates that Sijiazhuang Mine suffers more serious mechanical effects. Moreover, the occurrence of tectonically deformed coal in the three mines was compared. A large amount of soft mylonite occurs in the No. 15 coal seam of Sijiazhuang Mine, and such tectonically deformed coal is prone to outburst hazards. In comparison, the No. 15 coal seam of Yangquan No. 5 Mine and Xinjing Mine in the north is firmer (Guoyangxinneng Co., 2010). A combination between the firmness coefficient results in Fig. 8 and the paleotemperature results in Fig. 4 reveals that the firmness coefficient generally decreases with the rise of paleotemperature. Magma intrusion may change the stress state of coal and bring additional tectonic stress. Consequently, coal gets broken and experiences a decrease in its firmness (Wang et al. 2011, 2013).

\subsection{Superimposed influence of deep additional thermal temperature field on the stress distribution and fold degree of coal seam}

The strain distribution of a coal seam is the direct reflection of its stress distribution. Due to the presence of magmatic rocks in the deep, the overlying coal seam is subjected to different thermal effects. In this process, different strains are produced, and the coal seam folds and bends to varying degrees. The coal seam closer to the heat source is subjected to stronger thermal stress and folds more severely. The similar phenomenon can be found in the explanation of tectonic migration. Some scholars suggest that the force of tectonic migration or the formation of folds and faults may result from the heterogeneous cooling process of strata (Tang et al. 2020).

In the original state free from the influence of thermal stress and other tectonic stress, the coal seam is mainly subjected to gravity lateral stress in the horizontal direction (Jiang et al. 2015):

$\sigma_{\mathrm{h}}=\frac{\mu}{1-\mu} \gamma H$

where, $\sigma_{\mathrm{h}}$ is the horizontal stress; $\mu$ is Poisson's ratio; $H$ is the buried depth; and $\gamma$ is the bulk density of overlying coal strata.

When subjected to the thermal action of magma, the coal seam will undergo thermal expansion, and new tectonic horizontal stress is added in the horizontal direction. Resultantly, folds and faults appear in the coal seam. At this time, the horizontal stress becomes:

$\sigma_{\mathrm{h}}^{\prime}=\sigma_{\mathrm{h}}+\sigma_{\mathrm{sh}}+\sigma_{\mathrm{th}}$ 

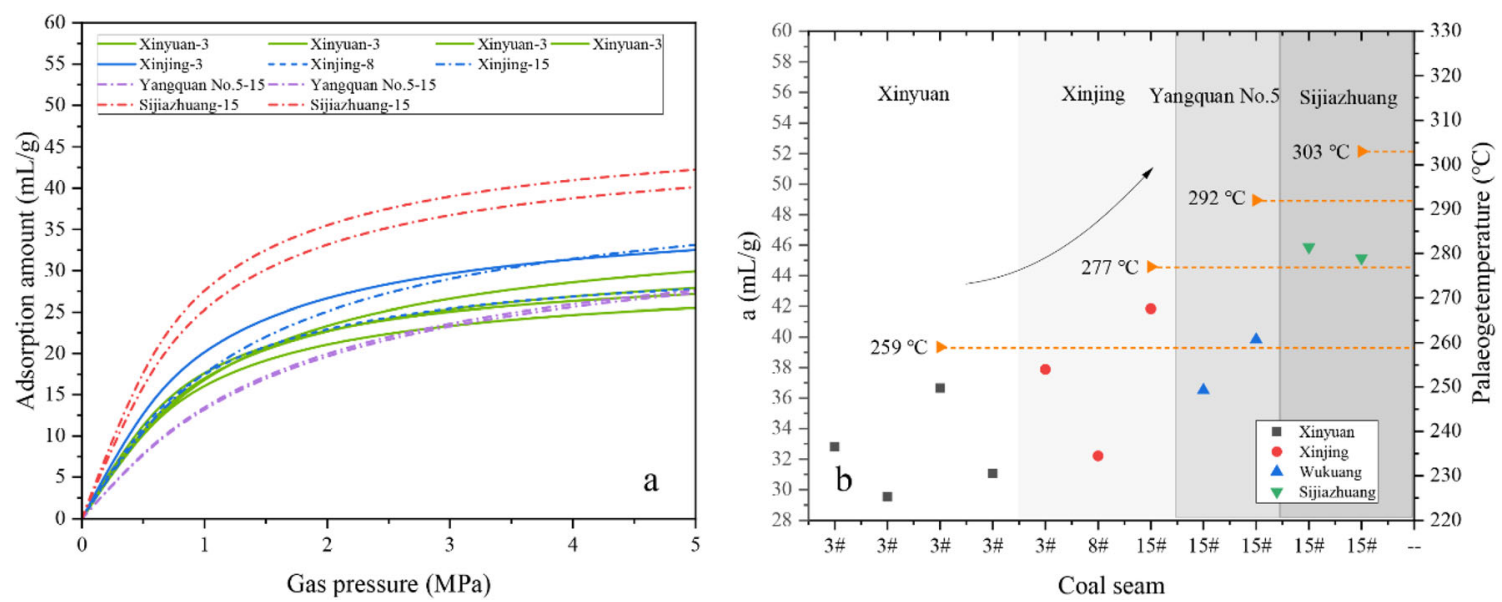

Fig. 7 Experimental results of adsorption capacities in typical mines of Yangquan mining area (a. Isothermal adsorption curves; b. $a$ values)

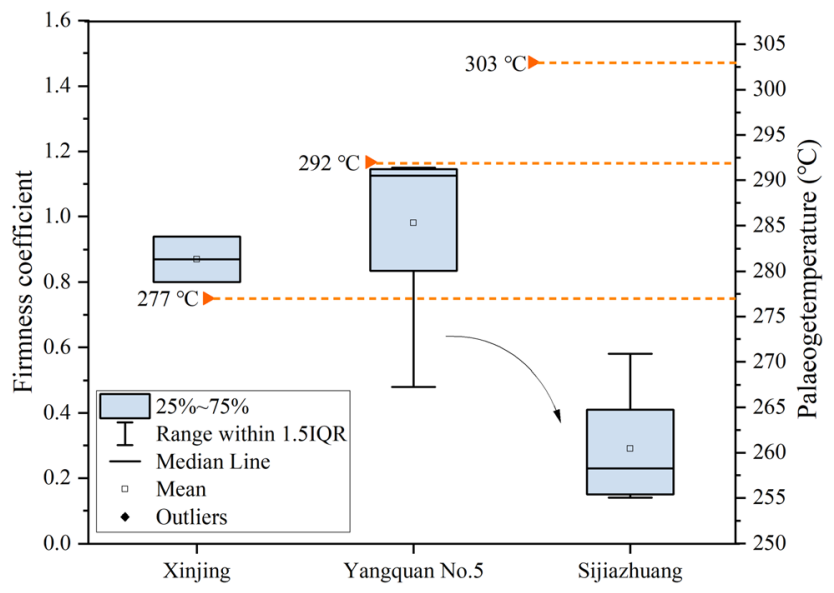

Fig. 8 Experimental results of firmness coefficients in typical mines of Yangquan mining area

where, $\sigma_{\mathrm{h}}^{\prime}$ is the new horizontal stress; $\sigma_{\mathrm{sh}}$ and $\sigma_{\mathrm{th}}$ are the tectonic horizontal stress and the horizontal stress caused by thermal expansion, respectively.

Thermal stress is generated when a heated coal seam fails to expand freely due to the limitation of external boundary conditions (Zhang et al. 2011). As the depth of the coal seam increases, the uniaxial strain boundary of gas-bearing coal body gradually transits to an isovolumetric boundary. Therefore, in the case of deep strata, the generation of subtle strain can cause notable changes in fractures, which will affect permeability and considerably impact gas migration. The relationship between thermal expansion strain of coal microelements and temperature can be expressed as (Guo et al. 2014):

$\mathrm{d} \varepsilon_{T}=\eta \mathrm{d} T$

where, $\varepsilon_{T}$ is the thermal expansion strain of coal microelements; $\eta$ is the coefficient of thermal expansion; $T$ is the temperature.
Thus, the higher the heating temperature, the greater the thermal strain of coal. Next, the temperature data obtained from Eq. (1) are substituted into Eq. (5), with the coefficient of thermal expansion and the initial temperature set as $38.13 \times 10^{-6} \mathrm{~K}^{-1}$ and $30{ }^{\circ} \mathrm{C}$, respectively. The maximum strains at Xinyuan Mine, Xinjing Mine, Yangquan No. 1 Mine, Yangquan No. 5 Mine and Sijiazhuang Mine are $0.87 \%$, $0.94 \%, 0.93 \%, 1 \%$ and $1.04 \%$, respectively. Figure 9 displays the distribution of the No. 3, No. 12 and No. 15 coal seams in Yangquan mining area (Tang et al. 2018; Wang et al. 1998). It can be observed from Fig. 9 that the No. 15 coal seam, which is closest to the magmatic rock below, has the most severe folds. In the horizontal direction ( $\mathrm{Li} \mathrm{2015a,} \mathrm{b)} \mathrm{found} \mathrm{that} \mathrm{the}$ number of folds in the No. 15 coal seam is larger in Yangquan No. 5 Mine than in Xinjing Mine. Besides, collapse columns, which are closely related to folds, are distributed more densely in the south where Yangquan No. 5 Mine is located $\left(9.61 / \mathrm{km}^{2}\right)$ than in the north where Xinjing Mine is located $\left(7.53 / \mathrm{km}^{2}\right)$. This phenomenon further verifies that RMTM has an important influence on Yangquan mining area (Pu et al. 2012). A large number of folds formed in the deep promote the possibility of forming gas-rich zones on the axis of the fold, hence increasing the risk of gas outburst.

\subsection{Influence of deep additional thermal temperature field on the deterioration of coal seam gas and permeability}

In addition to the distribution of coal seam, the permeability of coal seam is also affected by the deep thermal temperature field. As can be known from Eq. (2), temperature will induce additional thermal strain on coal microelements. The thermal strain formed by the temperature variation resembles the adsorption expansion of coal. Therefore, the volumetric deformation of the fracture-matrix dual-porosity medium considering the adsorption 
expansion and the thermal effect can be written as (Guo et al. 2014):

$\frac{\mathrm{d} V}{V}=-\frac{1}{K}(\mathrm{~d} \bar{\sigma}-\alpha \mathrm{d} p)+\left(1-f_{\mathrm{m}}\right)(1-\phi) \mathrm{d} \varepsilon_{\mathrm{m}}$

where, $V$ is the volume of coal; $K$ is the bulk modulus of coal; $\bar{\sigma}$ is the average stress; $\alpha$ is the effective stress coefficient; $p$ is the gas pressure; $f_{\mathrm{m}}$ is the influence coefficient of coal matrix on coal fracture deformation; $\varphi$ is the porosity; $\varepsilon$ is the strain caused by adsorption and temperature.

$\mathrm{d} \varepsilon_{m}=\mathrm{d} \varepsilon_{\mathrm{s}}+\mathrm{d} \varepsilon_{T}$

where, $\varepsilon_{\mathrm{s}}$ is the adsorption strain.

In the case of deep strata, the uniaxial strain condition dominated by stress gradually changes to the isovolumetric condition controlled by strain (Liu et al. 2016; Zoback et al. 2010; Lu et al. 2016) (Fig. 10). Then, there exists a relationship:

$\frac{\mathrm{d} V}{V}=0$

If the effective stress coefficient $\alpha \approx 1$, Eq. (9) can be obtained by substituting Eqs. (5), (7) and (8) into Eq. (6):

$\mathrm{d} \bar{\sigma}-\mathrm{d} p=K\left(1-f_{\mathrm{m}}\right)(1-\phi)\left(\mathrm{d} \varepsilon_{\mathrm{s}}+\eta \mathrm{d} T\right)$

In the case of deep strata, a slight change in temperature (dT) can lead to a huge change in effective stress, which in turn affects the crack opening as well as the gas pressure value. Lu (2016) once gave the function of coal seam permeability variation under the isovolumetric condition in the deep:

$\frac{k}{k_{0}}=\exp \left\{-\frac{C_{\mathrm{f}} E}{(1-2 v)}\left[\frac{\varepsilon_{\max }\left(p-p_{0}\right)}{\left(p+p_{\varepsilon}\right)\left(p_{0}+p_{\varepsilon}\right)}\right]\right\}$

where, $k_{0}$ and $k$ are the initial permeability and the permeability, respectively; $c_{\mathrm{f}}$ is the reciprocal of the fracture bulk modulus; $\varepsilon_{\max }$ is the maximum strain caused by adsorption; $p_{\varepsilon}$ is the adsorption strain constant.

By introducing it into the thermal strain, Eq. (10) can be changed into:

$\frac{k}{k_{0}}=\exp \left\{-\frac{C_{\mathrm{f}} E}{(1-2 v)}\left[\begin{array}{r}\frac{\varepsilon_{\max }\left(p-p_{0}\right)}{\left(p+p_{\varepsilon}\right)\left(p_{0}+p_{\varepsilon}\right)} \\ +\eta\left(T-T_{0}\right)\end{array}\right]\right\}$

According to Eq. (11), the variation of coal seam permeability with buried depth at different temperatures (277 ${ }^{\circ} \mathrm{C}$ in Xinjing Mine, $292{ }^{\circ} \mathrm{C}$ in Yangquan No. 5 Mine and $303{ }^{\circ} \mathrm{C}$ in Sijiachang Mine) are observed with reference to the variation rule of measured average pressure in the deep of the No. 15 coal seam with the buried depth $P=0.0025$

$\mathrm{H}$. The observation results are plotted in Fig. 11.

It can be found that under the condition of deep strata, a higher ground temperature corresponds to a lower
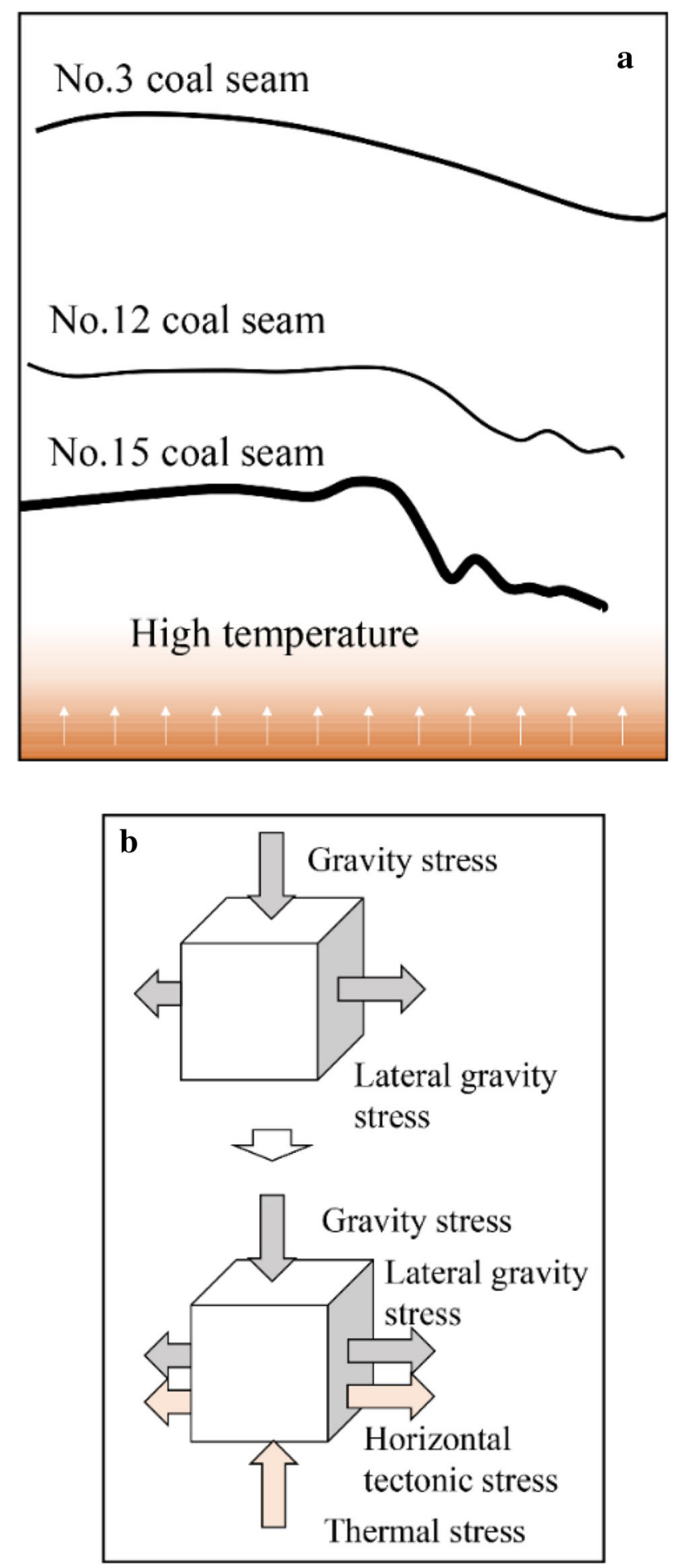

Fig. 9 Sketch map of the influence of magma on coal seam occurrence in Yangquan mining area

permeability of coal seam. Accordingly, it is easier to preserve gas, which indirectly maintains the gas pressure at a higher level.

In conclusion, the influence of RMTM on the coal seam in Yangquan mining area is mainly exhibited in three aspects: 


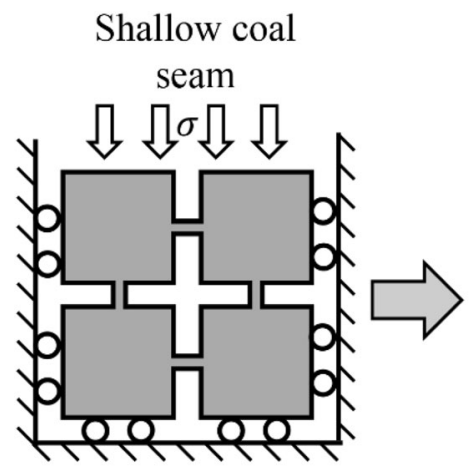

a Uniaxial strain condition
Deep coal seam

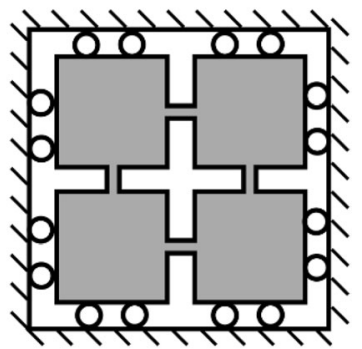

b Isovolumetric condition

Fig. 10 Model boundary variation at different depths

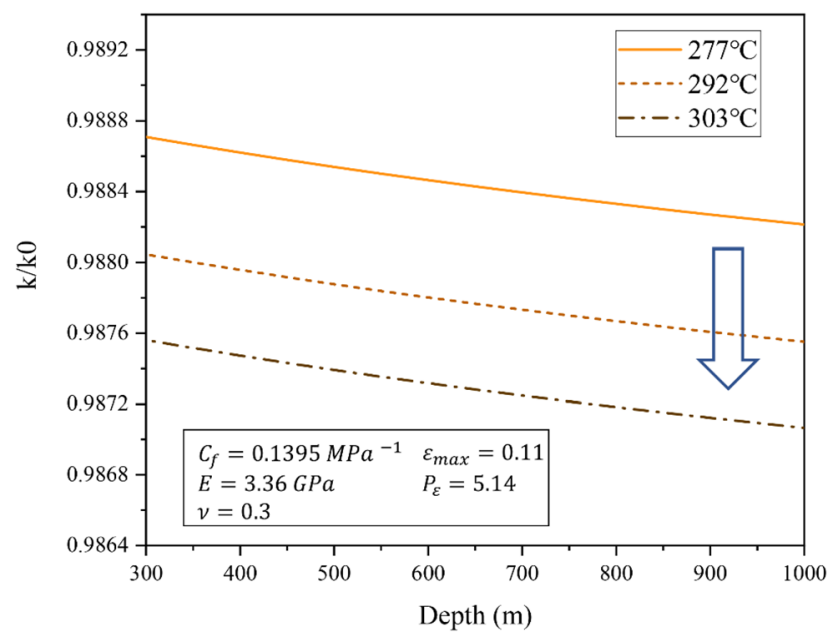

Fig. 11 Relationship between permeability and buried depth under different paleotemperatures

(1) increasing the gas adsorption ability of the coal seam and improving the supply ability of the gas source; (2) increasing the bending degree of folds, thus providing a place for gas accumulation; (3) reducing the permeability of the coal seam, thus forming a large area of low-permeability zone. These actions make it easier to form low-permeability zones or gas-rich zones, which will greatly enhance the risk of gas outburst. In the vertical direction, the greater the depth, the higher the risk, while in the horizontal direction, the stronger the thermal effect, the higher the risk of outburst.

\section{Validation of gas outburst risk distribution in Yangquan mining area}

\subsection{Gas pressure distribution}

Figure 12 summarizes the measured values of gas pressure in different coal seams of Yangquan No. 5 Mine,

Sijiazhuang Mine and Xinjing Mine. In general, the gas pressure shows a trend of Sijiazhuang $>$ Xinjing $>$ No. 5, which is slightly different from the geothermal distribution (Sijiazhuang $>$ No. $5>$ Xinjing). The main reasons are as follows: First, since the mining activities in Yangquan No. 5 Mine started earlier, gas in the mine has been extracted or has escaped via ventilation. Second, in addition to thermal stress, Yangquan No. 5 Mine is also subjected to regional plate stress. As a result, many regional faults are formed there, serving as gas escape channels. However, with respect to the deep coal seam where gas is well sealed, the gas pressure of Yangquan No. 5 Mine gradually approaches that of Xinjing Mine, even exceeding the measured value of Xinjing Mine in the No. 15 coal seam (in the red box). The characteristic of high gas pressure in the south and low gas pressure in the north of the No. 15 coal seam agrees with the distribution of gas content contour map obtained by Tang (2018). This proves the rationality of the abovementioned ground temperature distribution law.

\subsection{Distribution of coal and gas outburst accidents}

Figure 13 shows the statistics of gas accidents in Sijiazhuang Mine, Yangquan No. 5 Mine and Xinjing Mine after the year 2000. A total of 21 dynamic outburst accidents occurred in Sijiazhuang Mine, all of which occurred in the No. 15 coal seam, with the maximum coal outburst quantity being $281.4 \mathrm{t}$. There were 6 outburst accidents in Yangquan No. 5 Mine. The latest one also occurred at the depth of $800 \mathrm{~m}$ in the No. 15 coal seam on May 13, 2014, with a coal outburst quantity of $325 \mathrm{t}$. Compared with the above two mines, Xinjing Mine has a relatively small mining depth. The latest one occurred in the coal roadway at a buried depth of $621.6 \mathrm{~m}$ on June 19, 2012, with a coal outburst quantity of $202.99 \mathrm{t}$. Vertically, the occurrence scale of outburst is positively correlated with the depth, but compared with the initial stage of shallow mining, the number of outburst accidents has decreased obviously through the treatment in recent years. Horizontally, Sijiazhuang Mine suffered the most outburst accidents (21 times), while the numbers of outburst accidents that occurred in Yangquan No. 5 Mine and Xinjing Mine are smaller ( 6 times and 7 times, respectively). As revealed by a combination between the outburst statistics in Fig. 13 and the paleotemperature results in Fig. 4, the distribution of maximum outburst size almost coincides with the distribution of maximum paleotemperature, demonstrating a strong relevance between the outburst risk and magmainduced thermal impact. 


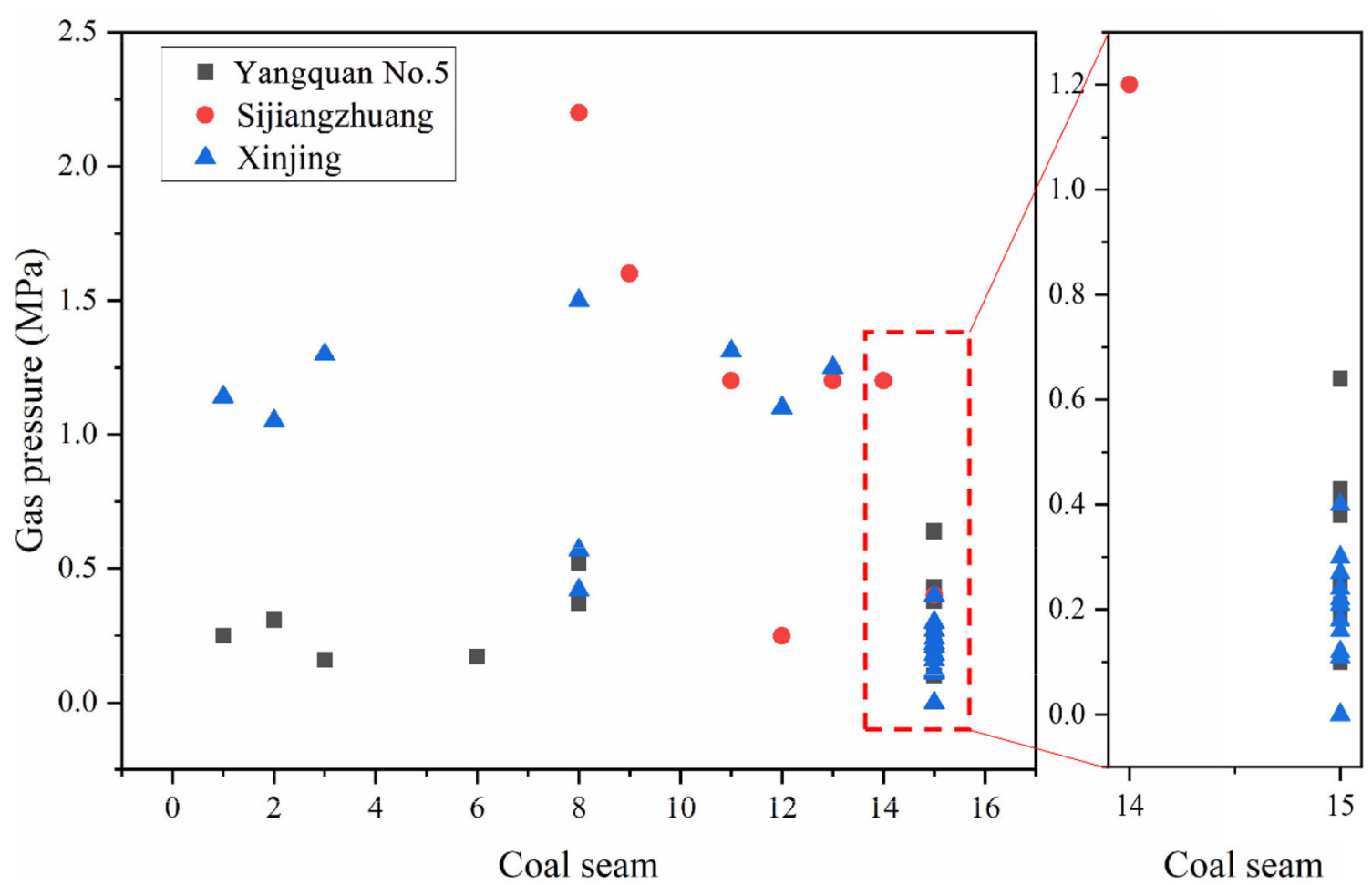

Fig. 12 Gas pressure in typical coal mines of Yangquan mining area

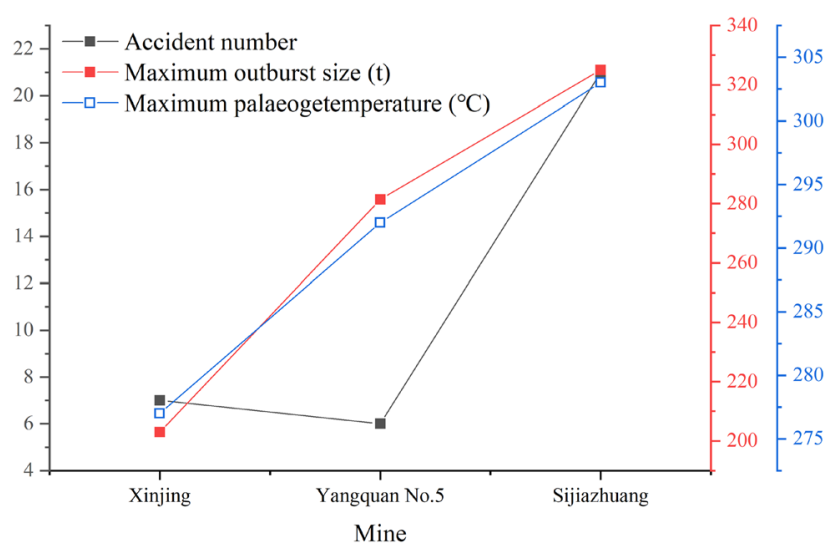

Fig. 13 Comparison of the numbers and sizes of outburst accidents in typical coal mines of Yangquan mining area after the year 2000

\section{Conclusions}

(1) The vitrinite reflectance test results show that the coal seams in Yangquan mining area are highly metamorphic in the south and less metamorphic in the north. The vitrinite reflectance of Sijiazhuang Mine is between $2.35 \%$ and $3.25 \%$, with an average of $2.88 \%$; that of Yangquan No. 5 Mine is between $2.90 \%$ and $2.98 \%$, with an average of $2.94 \%$; and that of Xinjing Mine is between $2.36 \%$ and $2.78 \%$, with an average of $2.61 \%$.
(2) The results of paleotemperature back-calculation indicate that Yangquan mining area has a higher paleotemperature in the south and a lower paleotemperature in the north. The maximum thermal evolution temperatures of Sijiazhuang Mine, Yangquan No. 5 Mine and Xinjing Mine are 303,292 and $283^{\circ} \mathrm{C}$, respectively.

(3) The magma-induced additional thermal metamorphism in the deep increases the limit adsorption capacity of coal seams in Yangquan mining area. At the same time, the additional thermal strain generated reduces the permeability of coal seams and intensifies the folds, which promotes the formation of gas-rich zones and increases the risk of gas outburst.

Acknowledgements The authors are grateful to the financial support from National Science and Technology Major Project of China: Demonstration project of coordinated exploitation of coalbed methane and coal in key coal mines of Shanxi province (2016ZX05067), and National Natural Science Foundation of China (51874314; 51904311).

Authors' contributions Jianshe Linghu: Conceptualization; Supervision; Writing-Review \& Editing. Wei Zhao: Visualization; WritingOriginal Draft. Jianbin Zhou: Supervision. Zhiming Yan: Supervision. Kai Wang: Supervision; Writing-Review \& Editing. Chao Xu: Visualization; Writing-Review \& Editing. Chuanwen Sun: WritingOriginal Draft

Funding National Science and Technology Major Project of China: Demonstration project of coordinated exploitation of coalbed methane and coal in key coal mines of Shanxi province 
(2016ZX05067). National Natural Science Foundation of China (51874314; 51904311).

Availability of data and materials The datasets used and/or analysed during the current study are available from the corresponding author on reasonable request.

\section{Declaration}

Conflicts of interests The author(s) declare(s) that they have no competing interests.

Open Access This article is licensed under a Creative Commons Attribution 4.0 International License, which permits use, sharing, adaptation, distribution and reproduction in any medium or format, as long as you give appropriate credit to the original author(s) and the source, provide a link to the Creative Commons licence, and indicate if changes were made. The images or other third party material in this article are included in the article's Creative Commons licence, unless indicated otherwise in a credit line to the material. If material is not included in the article's Creative Commons licence and your intended use is not permitted by statutory regulation or exceeds the permitted use, you will need to obtain permission directly from the copyright holder. To view a copy of this licence, visit http://creativecommons. org/licenses/by/4.0/.

\section{References}

Cao D, Nie J, Wang A et al (2018) Structural and thermal control of enrichment conditions of coal measure gases in Linxing block of eastern ordos Basin. J China Coal Soc 43(6):1526-1532

Cheng J, Wang X, Wang X (2009) The thermal history of the Qinshui Basin in Shanxi Province. Geoscience 23(6):1093-1099

Feng C, Yang Y, Shi Y (2014) Study on the selection evaluation of coalbed methane drainage area in Qinshui Basin based on geological characteristics. Yunnan Coal 3:79-84

Fu Deliang Xu, Guosheng ML, Yang Fu, Dan He, Zhonghui D, Ma $\mathrm{Yu}$ (2020) Gas generation from coal: taking Jurassic coal in the Minhe Basin as an example. Int J Coal Sci Technol 7(3):611-622

Guo P (2014) Research on laminar spallation mechanism of coal and gas outburst propagation. China University of Mining and Technology, Xuzhou

Guoyangxinneng Co., LTD (2010) China University of Mining and Technology. Safe and efficient technology of coal and gas comining in Yangquan mining area: Research and practice

Jiang Y (2015) Stress distribution of magmatic evolution tectonic zone and its controlling effect on gas dynamic disaster in the Haizi coalfield. China University of Mining and Technology, Xuzhou

Jiang J, Cheng Y, Wang L et al (2011) Petrographic and geochemical effects of sill intrusions on coal and their implications for gas outbursts in the Wolonghu mine, Huaibei Coalfield. China International Journal of Coal Geology 88(1):55-66

Jiao X, Wang Y (1999) Analysis of the geology structure charactor and forming system in Yangquan mine. Coal Technology 6:34-35

Jun $\mathrm{T}$ (2018) The division of cbm development unit of key coal mining area in Shanxi Province. China University of Mining and Technology, Xuzhou

Li C (2015a) Study on the distributing characteristics of karst collapse pillars in yangquan mining area and its relationship with folds, faults and seismicity. University of Technology, Taiyuan
Li L (2015b) Structural features and formation mechanism of Yangquan Xinjing Coalmine. China University of Mining and Technology, Xuzhou

Liu S, Wang Y, Harpalani S (2016) Anisotropy characteristics of coal shrinkage/swelling and its impact on coal permeability evolution with $\mathrm{CO}_{2}$ injection. Greenhous Gas Sci Technol 6(5):615-632

Lu S, Cheng Y, Li W (2016) Model development and analysis of the evolution of coal permeability under different boundary conditions. J Natural Gas Sci Eng 31:129-138

$\mathrm{Pu}$ W (2012) Coal metamorphism sequence of the Qinshui basin and its response to the deep process evolution. Taiyuan University of Technology, Taiyuan

Sweeney J J, Burnham A K. (1990) Evaluation of a simple model of vitrinite reflectance based on chemical kinetics AAPG Bulletin, (74): $1559-1570$

Tang Z (2018) The regional tectonic evolution and its control mechanism for structural development in Yangquan coalfield. China University of Mining and Technology, Xuzhou

Tang C A, Webb A A G, Moore W B, Wang Y Y, Ma T H, Chen T T. (2020) Breaking Earth's shell into a global plate network. Nature Communications, 11(1)

Wang Y (2014) Mesozoic-Cenozoic structural deformation and tectonic stress field characteristics in the Qinshui Basin. Nanjing University, Nanjing

Wang L, Cheng Y, Nie Z et al (2011) Effect s of an extremely thick igneous rock on gas occurrence and outburst disasters in a coal seam. J China Univ Min Technol 40(1):29-34

Wang W, Cheng Y, Wang L et al (2014) The controlling effect of extremely thick igneous rocks on gas occurrence of underlying coal seam. Journal of Mining and Safety Engineering 31(1):154-160

Wang L, Cheng Y, Zhai Q et al (2013) Effects of an extremely thick igneous rock on gas occurrence and outburst disasters in a coal seam. J China Coal Soc 38(8):1368-1375

Wang Y, Qin H, Jiao X (1998) Features and formation mechanism of geological structure in yangquan mining area. Coal Geology \& Exploration 6:24-27

Wang Q, Zhang S, Lu L et al (2017) Tectonic thermal evolution history in Qinshui Basin. Coal Geology of China 29(3):10-14

Wei Z, Kai W, Rong Z, Huzi D, Zhen L, Fenghua An (2020) Influence of combination forms of intact sub-layer and tectonically deformed sub-layer of coal on the gas drainage performance of boreholes: a numerical study. Int J Coal Sci Technol 7(3):571-580

Wu C, Qin Y, Fu X (2005) Microcosmic dynamical energies of coalbed gas reservoir formation of Qinshui Basin. Shanxi Province Geoscience 019(3):449-457

Xin Wu, Peng Yawen Xu, Jiang YQ, Wen N, Tingting Z (2020) Experimental study on evolution law for particle breakage during coal and gas outburst. Int J Coal Sci Technol 7(1):97-106

Yangquan Coal Industry (Group) Co., Ltd (2018) Research on safe and efficient integrated-drilling technology and equipment in floor rock roadway: Xinjing Mine. University of Mining and Technology, China

Yangquan Coal Industry (Group) Co., Ltd. (2018b) Research on safe and efficient integrated-drilling technology and equipment in floor rock roadway: Sijiazhuang Mine. China University of Mining and Technology

Zhang Y (2008) Geochemical kinetics. Princeton University Press

Zhang D (2011) Experimental study on mechanical characteristics and seepage characteristics of coal containing methane under the coupling effect between stress and thermal. Chongqing University, Chongqing

Zhao W, Cheng Y, Jiang H et al (2015) Role of the rapid gas desorption of coal powders in the development stage of 
outbursts. Journal of Natural Gas Science \& Engineering 28:491-501

Zhao W, Cheng Y, Pan Z et al (2019) Gas diffusion in coal particles: A review of mathematical models and their applications. Fuel 252:77-100

Zhao W, Cheng Y, Yuan M, An F (2014) Effect of adsorption contact time on coking coal particle desorption characteristics. Energy Fuels 28(4):2287-2296
Zhao W, Wang K, Liu S et al (2020) Asynchronous difference in dynamic characteristics of adsorption swelling and mechanical compression of coal: Modeling and experiments. Int J Rock Mechan Min Sci 135:104498

Zoback MD (2010) Reservoir geomechanics. Cambridge University Press 